\section{A technical tip for maintaining the orientation of circular resection specimens}

\author{
James David Bedford, \\ Syed Haroon Ali Shah
}

Department of Plastic Surgery and Burns, Royal Preston Hospital, Lancashire, UK

\section{Abstract}

In the excision of potentially malignant skin lesions, it is a surgeon's duty to assist the pathologist in correctly orientating the specimen submitted for histological examination. The use of marker sutures by surgeons to indicate the orientation of resection specimens is commonplace, but we realized that the excision of a small, circular lesion with a neat, circular excision margin can be the undoing of even the most attentive surgeon, if the correct orientation is lost before the marker is placed. We present a simple extra step that a surgeon can take to ensure that his or her specimen's orientation is preserved.

After excising a potentially malignant skin lesion, it is a surgeon's duty to assist the pathologist in correctly orientating the specimen submitted for histological examination. After processing the specimen, the pathologist will provide the surgeon with information on the proximity of malignant tumor cells to the surgical margin: this information may be important in planning re-excision or adjuvant therapy should the microscopic margins be too narrow, or if the resection is incomplete. The method described below is one way to help the surgeon to orientate circular specimens, and to prevent confusion over the location of involved or inadequate margins.To provide the pathologist with a point of reference for the orientation of resection specimens, surgeons will commonly mark one aspect of the specimen with a suture, ${ }^{1,2}$ these marker sutures are generally placed once the lesion has been removed from the patient and placed on the drapes. We noted that the excision of a small, circular lesion with a neat, circular excision margin, as is often done when creating defects on the face for reconstruction with skin grafts and local flaps, can be the undoing of even the most attentive surgeon. These homogenous discs can be very easily skewed or rotated and the correct orientation lost before the marker suture is placed.

Our solution is to add a simple, five second step to the pre-operative marking stage: once the lesion (dotted line) and surgical margins (solid line) are marked, we also ink a perpendicular bold line abutting the surgical margin, as illustrated in Figure 1. This bold mark will be the site of the marker suture, and its position is recorded on our theatre whiteboard before the procedure, for example marker suture lateral margin. When, following excision, the suture is finally placed, orientation of the specimen is reconfirmed and it is passed off the field. When submitting the specimen for histology, we always describe the marker suture as being at 12 o'clock on the request form. Out pathologists have told us that this makes it easier for them to comment on marginal involvement, as rather than having to work out which part of the specimen is medial, lateral, anterior, posterior, proximal, or distal, they can reference margins by their position on the clock face. An example of this may be: tumor is present at the 3 o'clock margin, but is at least $4 \mathrm{~mm}$ from the 6, 9 and $12 o^{\prime}$ 'clock margins.

When the post-operative note is completed the orientation is included, often pictorially, but always in writing, such as marker suture lateral = $12 o^{\prime}$ clock. Consequently, if there is marginal involvement or inadequate clearance on histology, the surgeon can easily determine the location of the involved margin from the pathologist's clock face description, and can

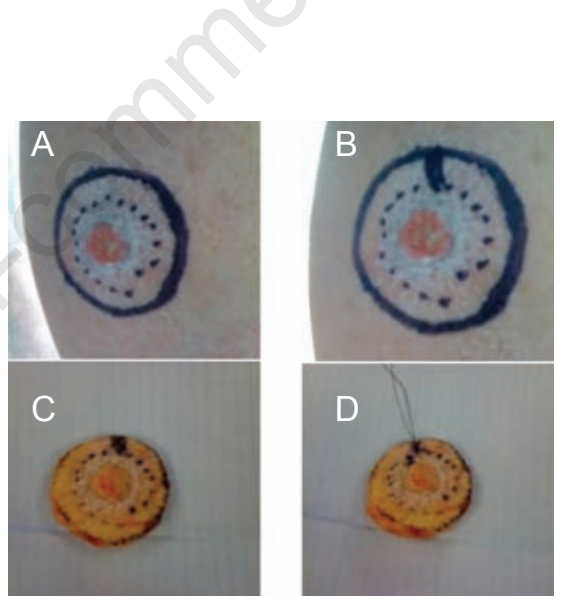

Figure 1. Illustration of the technique. The lesion is marked (dotted line) along with an appropriate surgical margin (solid line) (A). A bold line is marked to orient the specimen (B) and marker suture lateral is recorded on the theatre whiteboard. Following excision, the only feature to indicate the specimen's correct orientation is the bold line (C), and the marker suture is placed here $(\mathrm{D})$.
Correspondence: James D. Bedford, Department of Plastic Surgery and Burns, Royal Preston Hospital, Sharoe Green Lane, Fulwood, Preston, PR2 9HT, UK.

Tel. +44.01772.522.945 - Fax: +44.0871.900.5424

E-mail james.bedford@nhs.net

Key words: skin neoplasms, diagnostic techniques, surgical.

Contributions: SHAS, developed the surgical technique described, provided the photographs and proofread the manuscript; JDB, wrote the manuscript.

Conflicts of interests: the authors declare no potential conflicts of interests.

Received for publication: 27 September 2011 Revision received: 1 February 2012.

Accepted for publication: 3 February 2012.

This work is licensed under a Creative Commons Attribution NonCommercial 3.0 License (CC BYNC 3.0).

(C)Copyright J.D.Bedford and S.H.A. Shah., 2012

Licensee PAGEPress, Italy

Surgical Techniques Development 2012; 2:e8

doi:10.4081/std.2012.e8

plan adjuvant treatment appropriately. We have occasionally used an identical method when taking deeper specimens, such as those occasions where a disc of fascia is taken separately when there is doubt over the deep clearance of the tumor. On these occasions we follow the method described above, and also place a second marker suture on the superficial surface of the specimen to allow the pathologist to orient it in three dimensions. We have found this to be a reliable method for the accurate orientation of small circular skin excision specimens. An additional benefit is to reduce confusion over the precise location of involved or inadequate surgical margins. We hope this suggestion will come in handy to others.

\section{References}

1. Mackey SP, Hettiartchy SP, Baker RHJ, Armstrong AP. Use of absorbable sutures to mark excised skin lesions. Plast Reconstr Surg 2005;116:1188-9.

2. Montgomery LL. Breast biopsy. In: King TA, Borgen PI, eds. Atlas of procedures in breast cancer surgery. 1st ed. Andover: Thomson; 2005; pp.3-10. 